\title{
Research and complete the processing technology of Son La oxide copper ores for the Tay Bac Minerals Joint Stock Company
}

\author{
Hien Thi Tran*, Phong Duc Pham \\ National Institute of Mining - Metallurgy science and technology, Hanoi, Vietnam
}

\section{ARTICLE INFO \\ Article history: \\ Received $18^{\text {th }}$ Jan. 2021 \\ Revised 09th May 2021 \\ Accepted $11^{\text {th }}$ June 2021}

Keywords:

Copper oxide ores,

Flotation,

Mineral Processing,

Song Pe copper mine.

\section{ABSTRACT}

The copper ore processing plant of the Tay Bac Minerals Joint Stock Company has been designed and operated to produce metallic copper from copper sulphide ores and copper oxide ores in Son La province. Copper sulphide ores are processed to produce copper concentrates with content of more than $20 \%$ Cu for the next processing stage, while copper oxide ores, with average content of $1 \div 3 \% \mathrm{Cu}$ and after grinding, are fed directly into hydrometallurgical processes to extract copper. However, this process requires large amount of chemicals. Therefore, the economic efficiency is not high. The National Institute of Mining - Metallurgy Science \& Technology has researched and proposed a reasonable technology process for Son La copper oxide ores for solving difficulties and perfecting the processing technology at the plant that improves economic efficiency and minimizes environmental pollutions. This report presents results of the experimental production research project with the code CNKK.013.19, implemented by the Institute of Materials Science and sponsored by the Ministry of Industry and Trade.

Copyright (C) 2021 Hanoi University of Mining and Geology. All rights reserved.

${ }^{*}$ Corresponding author

E - mail: hienvimluki@gmail.com

DOI: 10.46326/JMES.2021.62(3b).03 


\title{
Nghiên cứu và hoàn thiện công nghệ tuyển quặng đồng oxit Sơn La của Công ty Cổ phần Khoáng sản Tây Bắc
}

\author{
Trần Thị Hiến *, Phạm Đức Phong \\ Viện Khoa học và Công nghệ Mỏ - Luyện kim, Hà Nội, Việt Nam
}

\begin{abstract}
THÔNG TIN BÀI BÁO
TÓM TẮT

Quá trình:

Nhận bài 18/01/2021

Sửa xong 09/5/2021

Chấp nhận đăng 11/06/2021

Tù khóa:

Mỏ đồng Song Pe

Quặng đồng oxit,

Tuyển khoáng,

Tuyển nổi.

Nhà máy chế biến quặng đồng thuộc Công ty Cổ phần Khoáng sản Tây Bắc đã đi vào hoat động sản xuất ra sản phẩm đồng kim loai tù̀ quăng đồng sunfua và quặng đồng oxit tại Son La; Đối với quặng đồng sunfua sau quá trinh tuyển đã thu được sản phẩm quặng tinh đồng đạt hàm lượng $\geq 20 \%$ cấp cho khâu chế biến tiếp theo. Đối với quặng đồng oxit sau khi được khai thác có hàm lương đồng tù̀ $1 \div 3 \%$ tiến hành nghiền min và đưa trực tiếp vào thủy luyện để sản xuất ra đồng kim loại, quá trình này đòi hỏi chi phí hóa chất (thuốc chiết) rất lớn, nên hiệu quả kinh tế chưa cao. Tù̀ vấn đề nêu trên, Viẹn Khoa học và Công nghê Mỏ - Luyện kim đã nghiên cúu đưa ra quy trình cồng nghệ tuyển hợp lý đối với quặng đồng oxit Son La, giải quyết những khó khăn và hoàn thiên công nghệ tại nhà máy, từ đó nâng cao hiệu quả kinh tế đồng thời giảm thiểu ô nhiếm môi truờng. Đây là kết quả nghiền cứu của dự án SXTN mã số CNKK.013.19 do Viện Khoa học vật liệu chủ trì thực hiện được tài trợ bởi Bộ Công thưong.
\end{abstract}

(C) 2021 Trường Đại học Mỏ - Địa chất. Tất cả các quyền được bảo đảm.

\section{Mở đầu}

Khoáng sản đồng ở nước ta phân bố ở nhiều nơi, song các mỏ có quy mô công nghiệp tập trung chủ yếu ở vùng Tây Bắc, các vùng khác chỉ có những mỏ và điểm quặng đơn lẻ, có quy mô nhỏ và ít có giá trị kinh tế.

Theo thống kê, Việt Nam có khoảng 1.874.380 tấn $\mathrm{Cu}$ kim loại, trong đó trữ lượng khai thác là 441.000 tấn, trữ lượng tài nguyên khoảng 983.843 tấn và tài nguyên dự báo là 449.537 tấn

*Tác giả liên hệ

E - mail: hienvimluki@gmail.com

DOI: 10.46326/JMES.2021.62(3b).03 đồng (QĐ 910 QĐ - TTg ngày 25/07/2018 Phê duyệt Quy hoạch thăm dò, khai thác, chế biến và sử dụng quặng vàng, đồng, niken, molipden đến năm 2025, có xét đến năm 2035, năm 2018).

Quặng đồng oxit phần lớn được thành tạo do quá trình thứ sinh, xảy ra ở tầng trên của quặng sulfua đồng. Đa số quặng oxit được khai thác đồng thời ở các mỏ quặng sulfua lớn. Các khoáng vật chứa đồng oxit phổ biến nhất là malachit, azurit, cuprit, tenorit, chrysocolla, atacamit, diopta, chalcantit và brochantit.

Các phương pháp thường áp dụng để tuyển quặng đồng oxit trên thế giới và ở Việt Nam bao gồm: phương pháp tuyển nổi, phương pháp tuyển trọng lực kết hợp tuyển nổi, phương pháp tuyển nổi kết hợp với tuyển từ, phương pháp hóa tuyển 
và phương pháp vi sinh vật. Tùy thuộc vào từng đối tượng quặng, nhu cầu về chất lượng sản phẩm và khả năng kỹ thuật mà áp dụng các phương pháp tuyển phù hợp (Nguyễn Bơi, 1998).

Công ty Cổ phần Khoáng sản Tây Bắc là đơn vị được Nhà nước cấp phép khai thác và chế biến hai mỏ đồng Sao Tua và Song Pe, là đơn vị duy nhất của tỉnh Sơn La đã đầu tư chế biến sâu khoáng sản quặng đồng đến sản phẩm đồng kim loại. Mỏ đồng Song Pe, huyện Bắc Yên, tỉnh Sơn La có trữ lượng và tài nguyên quặng đồng được xác định là 62.597 tấn quặng, tương ứng 1.096,80 tấn đồng kim loại, hàm lượng quặng đồng oxit dao động từ $1 \div 3 \% \mathrm{Cu}$, quặng sunfua có hàm lượng từ $0,8 \div 5 \% \mathrm{Cu}$, trung bình khoảng $1 \div 2 \% \mathrm{Cu}$.

\section{+) Công nghệ tuyển quặng sunfua}

Công nghệ tuyển quặng đồng sunfua tại Công ty Cổ phần Khoáng Sản Tây Bắc được mô tả như sau: Quặng đầu sau khi đập - sàng được đưa vào máy nghiền bi, sản phẩm sau máy nghiền bi được cấp vào thiết bị phân cấp ruột xoắn. Bùn tràn phân cấp ruột xoắn có độ hạt đến 85\% cấp - 0,074 mm được đưa vào khâu tuyển nổi đồng, cấp hạt thô $+0,074$ mm được cấp lại máy nghiền bi để nghiền lại. Sơ đồ tuyển nổi gồm 01 khâu tuyển chính, 03 khâu tuyển tinh và 02 khâu tuyển vét. Sản phẩm quặng tinh đồng nhận được có hàm lượng> 20\% Cu với thực thu đồng tương ứng là $85 \div 90 \%$.

\section{+) Công nghệ chế biến quặng đồng oxit}

Các công trình nghiên cứu công nghệ tuyển quặng đồng ở Việt Nam chủ yếu tập trung vào đối tượng quặng đồng sunfua. Quặng đồng oxit của Việt Nam chiếm tỷ trọng không lớn và quy mô của các cơ sở chế biến thường rất nhỏ. Công nghệ tuyển quặng đồng oxit chưa được nghiên cứu sâu và chưa có phương án tuyển hiệu quả (Trần Thị Hiến, 2012). Hiện nay, trên thế giới đã có nhiều nghiên cứu tuyển quặng đồng oxit ở các chế độ công nghệ và thuốc tuyển khác nhau và đều cho kết quả tuyển khả quan (Xiong và nnk, 2012; Dandan Wu, Wenhui Ma, 2017; Peilun Shen, Dianwen Liu, 2019).

Đối với quặng đồng oxit tại Công ty Cổ phần Khoáng Sản Tây Bắc có hàm lượng $1 \div 3 \% \mathrm{Cu}$, không qua khâu tuyển để loại bỏ đất đá tạp mà được dùng trực tiếp theo công nghệ thủy luyện như sơ đồ Hình 1. Quặng đồng oxit được nghiền mịn đến $50 \mu \mathrm{m}$ sau đó hòa tách trong dung dịch

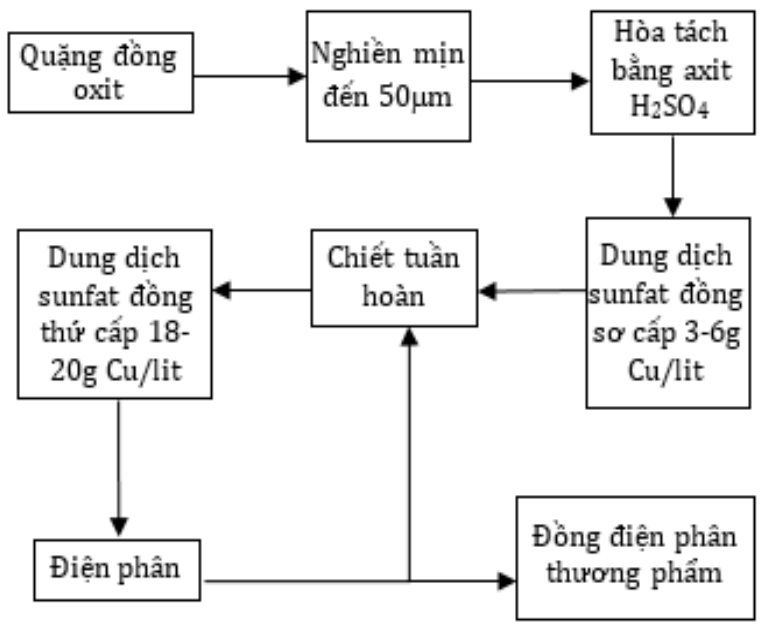

Hình 1. So đồ quy trình chế biến quặng đồng oxit Son La thành kim loại đồng điện phân.

axit sunfuric thu được dịch sunfat đồng có hàm lượng $\mathrm{Cu} 3 \div 6 \mathrm{~g}$ /lít và tiếp tục chiết làm sạch và nâng cao hàm lượng Cu lên $18 \div 20 \mathrm{~g} / \mathrm{lít}$ sau đó điện phân ra đồng tấm với công suất khoảng 1 tấn/ngày đêm. Do quặng đồng oxit không được làm giàu qua quá trình tuyển dẫn đến quy trình thủy luyện quặng đồng oxit đòi hỏi chi phí hóa chất (thuốc chiết) rất lớn, nên hiệu quả kinh tế chưa cao.

Từ các vấn đề nêu trên, việc nghiên cứu và hoàn thiện công nghệ tuyển quặng đồng oxit Sơn La của Cồng ty Cổ phần Khoáng sản Tây Bắc nhằm thu được sản phẩm quặng tinh đồng đạt hàm lượng $>20 \% \mathrm{Cu}$, thực thu đồng $\geq 50 \%$ cấp cho khâu chế biến tiếp theo (Hợp đồng số 26/KHVL ngày 02/03/2020 thực hiện Dự án SXTN nhánh KHCN giữa Viện Khoa học Vật liệu và Viện Khoa học và Công nghệ Mỏ - Luyện kim) là vấn đề có tính khoa học và thực tiễn.

\section{Phương pháp nghiên cứu}

Các thí nghiệm tuyển điều kiện được thực hiện theo phương pháp truyền thống, cố định các thông số khác ngoài thông số khảo sát. Kết quả tối ưu thí nghiệm trước được sử dụng cho thí nghiệm tiếp theo. Các thí nghiệm được thực hiện tại Phòng Công nghệ Tuyển khoáng và Trung tâm Nghiên cứu và Triển khai ứng dụng Công nghệ thuộc Viện Khoa học và Công nghệ Mỏ - Luyện kim.

Để xác định thành phần khoáng vật, hàm lượng đồng và các tạp chất trong quặng nguyên khai và các sản phẩm tuyển, nghiên cứu đã dùng 
các phương pháp phân tích sau: Các mẫu khoáng tướng thạch học được phân tích dưới kính hiển vi phân cực Axioskop 40 PL và phân tích rơnghen bằng thiết bị Empyrean (Panalytical - Hà Lan); các mẫu phân tích hóa xác định hàm lượng $\mathrm{Cu}$ sử dụng phương pháp phân tích quang phổ hấp phụ nguyên tử và quang phổ cảm ứng. Mẫu phân tích được thực hiện tại các trung tâm phân tích có uy tín trong nước: Viện Địa Chất - Viện Hàn lâm Khoa học và Công nghệ Việt Nam, Trung tâm Phân tích Thí nghiệm Địa chất - Tổng cục Địa chất và Khoáng sản và Trung tâm Phân tích hóa lý thuộc Viện Khoa học và Công nghệ Mỏ - Luyện kim.

\section{Kết quả nghiên cứu phát triển và hoàn thiện công nghệ tuyển quặng đồng oxit Son La}

Mẫu nghiên cứu công nghệ tuyển quặng đồng oxit mỏ đồng Bản Ngậm, xã Song Pe, huyện Bắc Yên, tỉnh Sơn La do Viện Khoa học Vật liệu - Viện Hàn lâm Khoa học và Công nghệ Việt Nam cung cấp. Mẫu nghiên cứu có khối lượng $3.000 \mathrm{~kg}$, bằng mắt thường nhận thấy, mẫu có màu nâu, vàng đất, bị phong hóa lên cấp hạt mịn nhiều, độ ẩm 9,34\%. Mẫu được trộn đều, giản lược, gia công để lấy được các mẫu phân tích khoáng tướng, thạch học, mẫu phân tích rơnghen, phân tích hóa, mẫu phân tích thành phần độ hạt và các mẫu thí nghiệm.

\subsection{Kết quả nghiên cúu thành phần vật chất mẫu}

- Kết quả phân tích thành phần hóa học mẫu quặng nguyên khai cho thấy, hàm lượng đồng từ $1,73 \div 1,85 \% \mathrm{Cu}$; các thành phần khác bao gồm: $\mathrm{SiO}_{2}=74,66 \% ; \sum \mathrm{Fe}=4,72 \%, S=0,10 \%$. Ngoài ra, các nguyên tố vàng, bạc trong mẫu có hàm lượng thấp lần lượt là $0,2 \mathrm{~g} / \mathrm{t} \mathrm{Au}$ và $6,3 \mathrm{~g} / \mathrm{t} \mathrm{Ag}$.

- Kết quả phân tích thành phần khoáng vật mẫu quặng nguyên khai, các khoáng vật chứa đồng bao gồm: malachit $2 \%$, chalcopyrit $<1 \%$, cuprit $<1 \%$, tetrahedrrit $<1 \%$. Các thành phần khoáng vật khác bao gồm: thạch anh $72 \%$, mica $18 \%$, felspat $2 \%$, chlorit $2 \%$, calcit $1 \%$, dolomit $1 \%$, goethit $1 \%$, hematit $<1 \%$.

- Kết quả phân tích thành phần độ hạt mẫu nghiên cứu đã được gia công xuống độ hạt - $2 \mathrm{~mm}$ được thể hiện tại Bảng 1, mức thu hoạch các cấp hạt có xu hướng giảm dần; hàm lượng đồng dao động $1,32 \div 2,82 \% \mathrm{Cu}$; hàm lượng đồng trong cấp hạt mịn $(-0,074 \mathrm{~mm})$ giàu hơn trong cấp hạt thô.
Phân bố đồng chủ yếu trong các cấp hạt - 1+0,5 $\mathrm{mm}$ (chiếm 47,04\%), cấp hạt - 2+1 mm ( chiếm 27,81\%), cấp hạt - 0,045 mm (chiếm 21,61\%).

Bảng 1. Kết quả phân tích thành phần độ hạt mẫu nghiên cúu.

\begin{tabular}{|c|c|c|c|c|c|c|}
\hline \multirow{2}{*}{ Cấp hạt (mm) } & \multicolumn{2}{|c|}{ Thu hoạch (\%) } & \multicolumn{2}{|c|}{ Hàm lượng Cu (\%) } & \multicolumn{2}{c|}{ Phân bố Cu (\%) } \\
\cline { 2 - 7 } & $\begin{array}{c}\text { Bộ } \\
\text { phận }\end{array}$ & $\begin{array}{c}\text { Lũy } \\
\text { tích }\end{array}$ & Bộ phận & $\begin{array}{c}\text { Lũy } \\
\text { tích }\end{array}$ & $\begin{array}{c}\text { Bộ } \\
\text { phận }\end{array}$ & $\begin{array}{c}\text { Lũy } \\
\text { tích }\end{array}$ \\
\hline$-2+1$ & 38,79 & 38,79 & 1,32 & 1,32 & 27,81 & 27,81 \\
\hline$-1+0,5$ & 20,70 & 59,49 & 1,71 & 1,46 & 19,23 & 47,04 \\
\hline$-0,5+0,25$ & 14,96 & 74,46 & 2,01 & 1,57 & 16,34 & 63,38 \\
\hline$-0,25+0,125$ & 4,45 & 78,90 & 2,23 & 1,60 & 5,39 & 68,76 \\
\hline$-0,125+0,074$ & 4,08 & 82,99 & 2,39 & 1,64 & 5,30 & 74,07 \\
\hline$-0,074+0,045$ & 2,90 & 85,89 & 2,74 & 1,68 & 4,32 & 78,39 \\
\hline$-0,045+0$ & 14,11 & 100,00 & 2,82 & 1,84 & 21,61 & 100,00 \\
\hline Quặng nguyên khai & 100,00 & & 1,84 & & 100,00 & \\
\hline
\end{tabular}

\subsection{Kết quả nghiên cúu xác lập các chế độ công nghệ tuyển}

Tổng hợp kết quả nghiên cứu xác lập chế độ công nghệ tuyển quặng đồng oxit khu vực Sơn La được thể hiện trên Bảng 2. Các chỉ tiêu công nghệ tuyển được thể hiện chi tiết trên đồ thị Hình $2 \div 8$.

Bảng 2. Tổng hợp kết quả nghiên cúu xác lập chế độ công nghệ tuyển.

\begin{tabular}{|c|c|c|c|}
\hline $\begin{array}{l}\text { Khâu } \\
\text { tuyển }\end{array}$ & TT & Chế độ công nghệ tuyển & Kết quả nghiên cứu \\
\hline \multirow{18}{*}{ 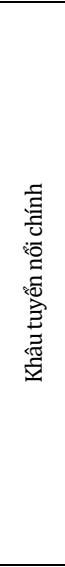 } & 1 & Chế độ mịn nghiền & \\
\hline & - & Độ mịn nghiền tối ưu & $\sim 90 \%-0,074 \mathrm{~mm}$ \\
\hline & 2 & Nồng độ bùn tuyển & \\
\hline & - & Tỷlệ R/L & $1 / 4$ \\
\hline & 3 & Chế độthuốc điều chỉnh môi trường & \\
\hline & - & Chi phí $\mathrm{Na}_{2} \mathrm{CO}_{3}$ & $1000 \mathrm{~g} / \mathrm{t}$ \\
\hline & - & Môi trường tuyển $\mathrm{pH}$ & 8,5 \\
\hline & 4 & Chế độ thuốc sunfua hóa bề mặt & \\
\hline & - & Chi phí $\mathrm{Na}_{2} \mathrm{~S}$ & $1500 \mathrm{~g} / \mathrm{t}$ \\
\hline & - & Chi phí $\left(\mathrm{NH}_{4}\right)_{2} \mathrm{SO}_{4}$ & $500 \mathrm{~g} / \mathrm{t}$ \\
\hline & 5 & Chế độ thuốc tập hợp & \\
\hline & - & Chủng loại thuốctập hợp & Sodium isoamyl xantat (SIAX) \\
\hline & - & Chi phí SIAX & $300 \mathrm{~g} / \mathrm{t}$ \\
\hline & 6 & Chế độ thuốc điều chỉnh bọt & \\
\hline & - & Chi phí dầu thông & $100 \mathrm{~g} / \mathrm{t}$ \\
\hline & 7 & Xác định số lần tuyển tinh, tuyển vét & \\
\hline & - & Số lần tuyển tinh & 2 \\
\hline & - & Số lần tuyển vét & 1 \\
\hline \multirow{4}{*}{ 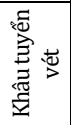 } & 1 & Chi phí $\mathrm{Na}_{2} \mathrm{~S}$ & $700 \mathrm{~g} / \mathrm{t}$ \\
\hline & 2 & Chi phí $\left(\mathrm{NH}_{4}\right)_{2} \mathrm{SO}_{4}$ & $150 \mathrm{~g} / \mathrm{t}$ \\
\hline & 3 & Chi phí SIAX & $100 \mathrm{~g} / \mathrm{t}$ \\
\hline & 4 & Chi phí dầu thông & $100 \mathrm{~g} / \mathrm{t}$ \\
\hline \multirow{6}{*}{ 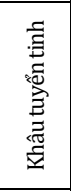 } & 1 & Khâu tuyển tinh 1 & \\
\hline & - & Chi phí $\mathrm{Na}_{2} \mathrm{CO}_{3}$ & $100 \mathrm{~g} / \mathrm{t}$ \\
\hline & - & Môi trường tuyển $\mathrm{pH}$ & 9 \\
\hline & 2 & Khâu tuyển tinh 2 & \\
\hline & - & Chi phí $\mathrm{Na}_{2} \mathrm{CO}_{3}$ & $750 \mathrm{~g} / \mathrm{t}$ \\
\hline & - & Môi trường tuyển $\mathrm{pH}$ & 9 \\
\hline \multirow{4}{*}{ 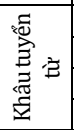 } & 1 & Nồng độ cấp liệu & \\
\hline & - & Tỷlệ R/L & $1 / 4$ \\
\hline & 2 & Cường độ từ trường tuyển từ & \\
\hline & - & Cường độ từ trường $\mathrm{H}$ & 12000 Gauss \\
\hline
\end{tabular}



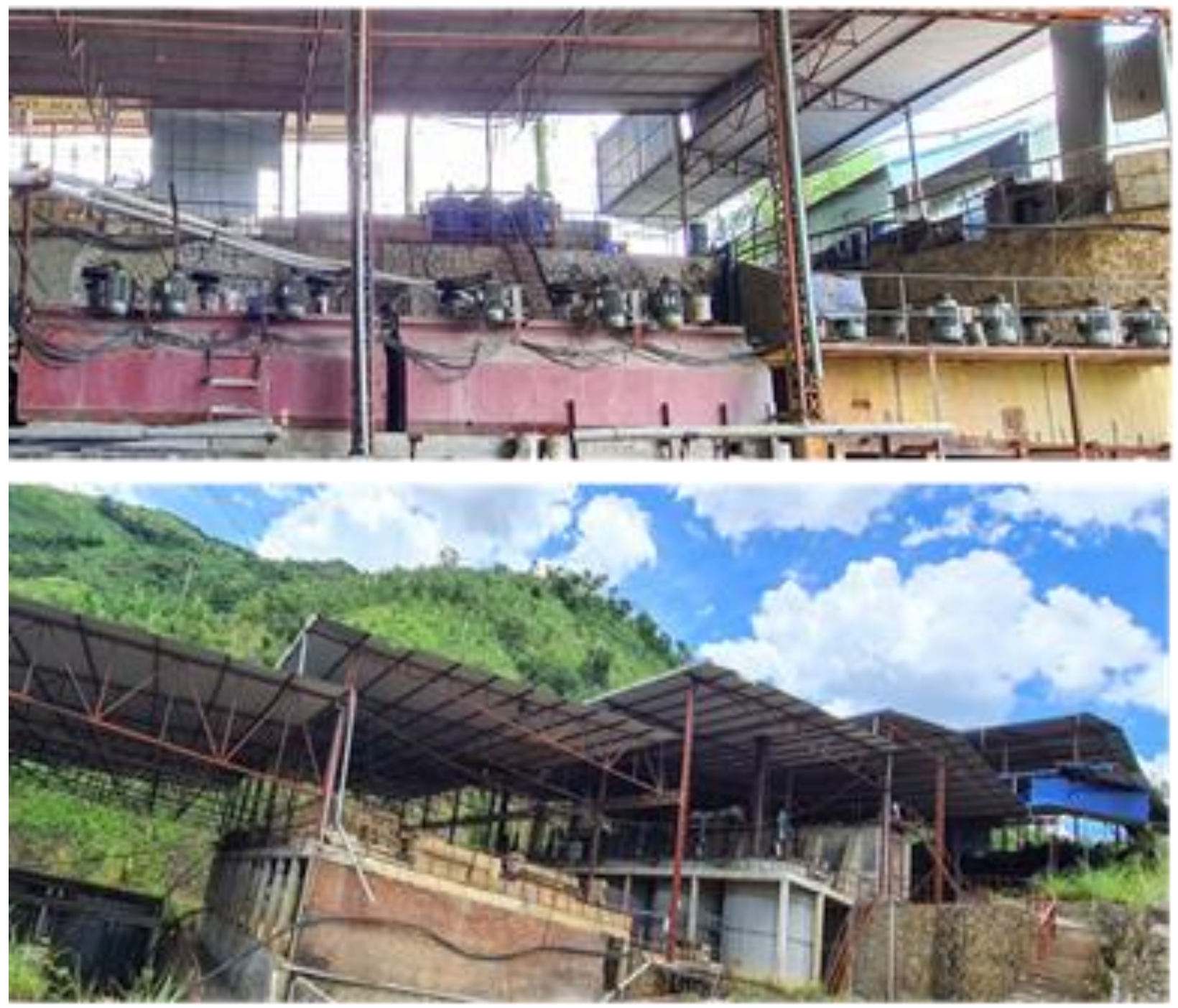

Hình 2. Nhà máy chế biến quặng đồng thuộc Công ty Cổ phần Khoáng sản Tây Bắc..

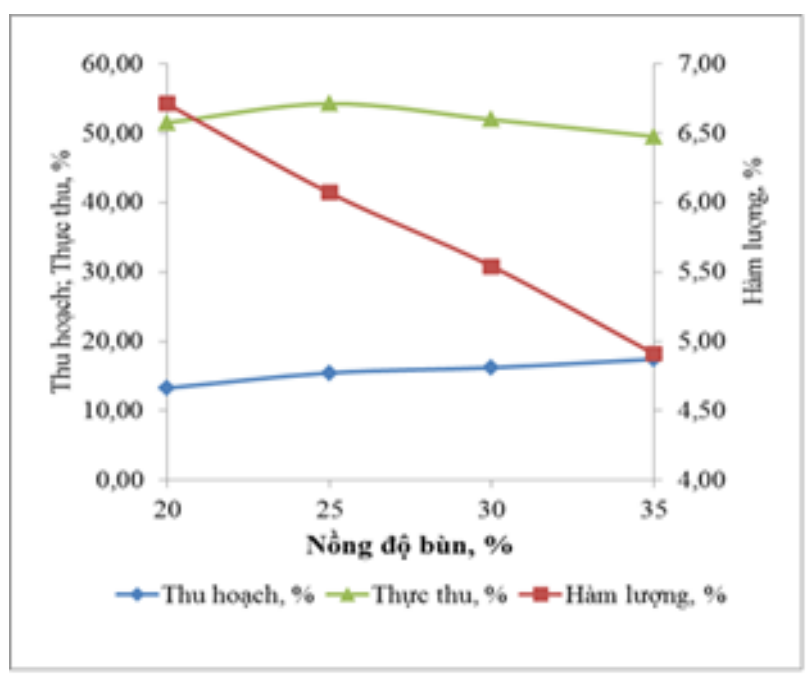

Hình 3. Đồ thị biểu diễn ảnh hương của nồng độ bùn đến hiệu quả tuyển.

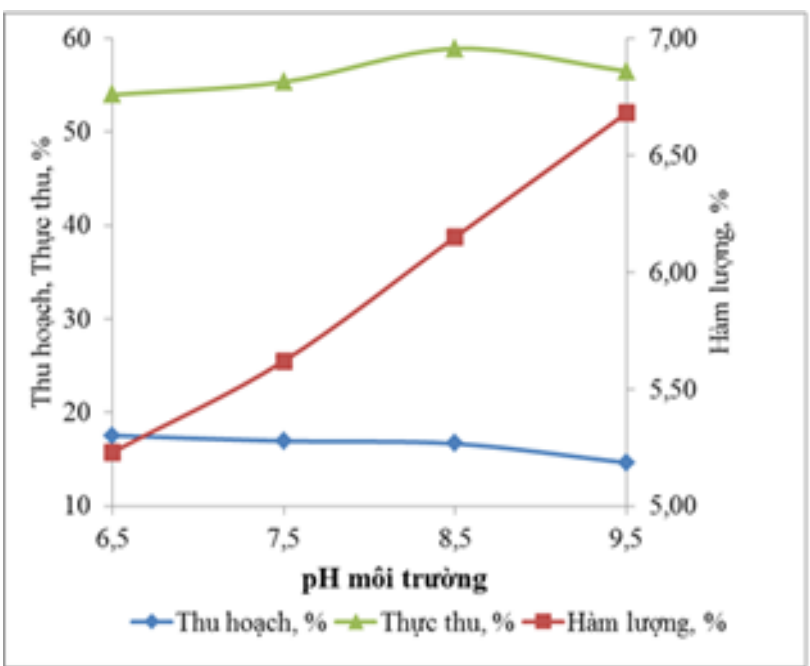

Hình 4. Đồ thị biểu diễn ảnh hưởng $p H$ đến hiệu quả tuyển. 


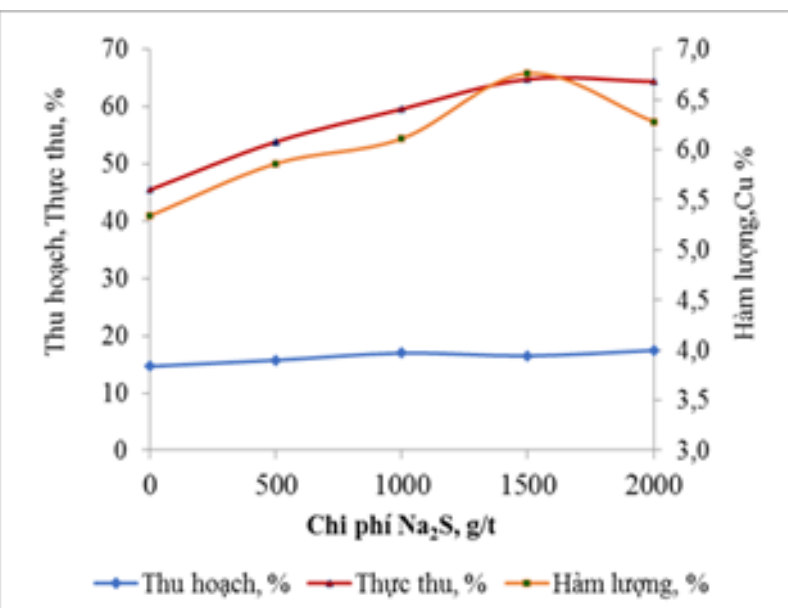

Hình 5. Đồ thị biểu diễn ảnh hưởng chi phí $\mathrm{Na}_{2} \mathrm{~S}$ đến hiệu quả tuyển.

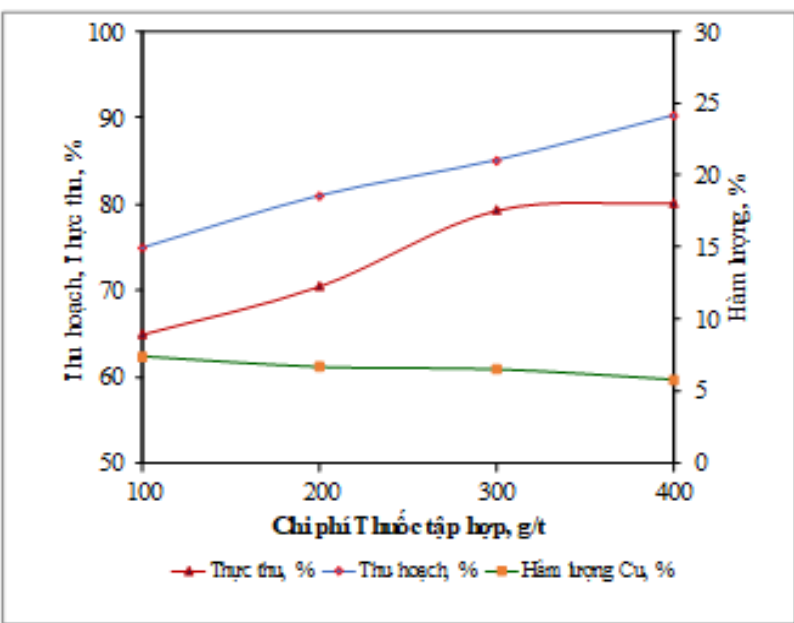

Hình 7. Đồ thị biểu diễn ảnh hưởng chi phí thuốc tập hợp đến hiệu quả tuyển.

\subsection{Kết quả thí nghiệm tuyển nổi sơ đồ vòng kín}

Nhóm tác giả đã xây dựng 02 sơ đồ thí nghiệm tuyển nổi vòng kín. Sơ đồ tuyển vòng kín 1 (Hình 9) - ưu tiên hàm lượng quặng tinh đồng, sử dụng phương pháp tuyển nổi để thu được sản phẩm quặng tinh đồng có mức thu hoạch 5,01\%, hàm lượng đồng là $22,90 \% \mathrm{Cu}$, thực thu đạt $66,28 \% \mathrm{Cu}$, kết quả tuyển thể hiện tại Bảng 3.

Bảng 3. Kết quả thí nghiệm sơ đồ vòng kín 1.

\begin{tabular}{|c|c|c|c|c|}
\hline TT & Tên sản phẩm & $\begin{array}{c}\text { Thu } \\
\text { hoạch, } \%\end{array}$ & $\begin{array}{c}\text { Hàm lượng } \\
\mathrm{Cu}, \%\end{array}$ & $\begin{array}{c}\text { Thực thu } \\
\mathrm{Cu}, \%\end{array}$ \\
\hline 1 & Quặng tinh đồng & 5,01 & 22,90 & 66,28 \\
\hline 2 & Thải & 94,99 & 0,61 & 33,72 \\
\hline & Quặng cấp & 100,00 & 1,73 & 100,00 \\
\hline
\end{tabular}

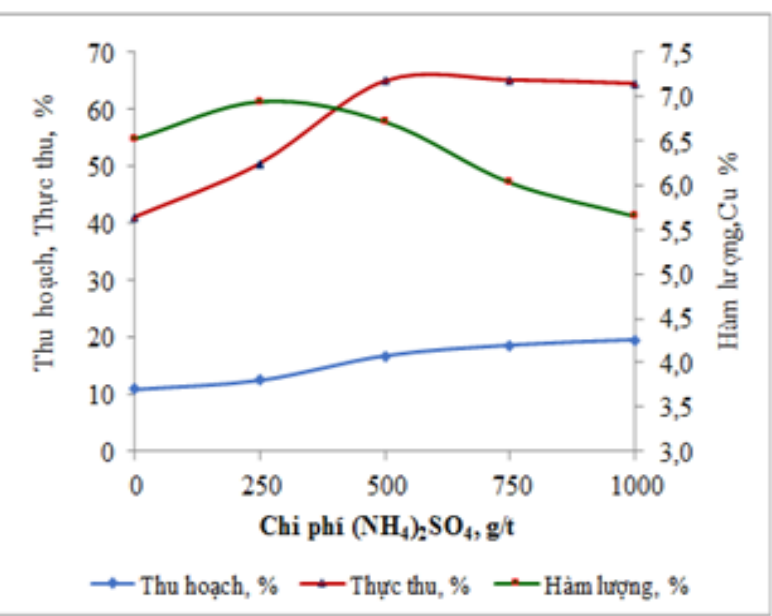

Hình 6. Đồ thị biểu diễn ảnh hương chi phí (NH4)2SO4 đến hiệu quả tuyển.

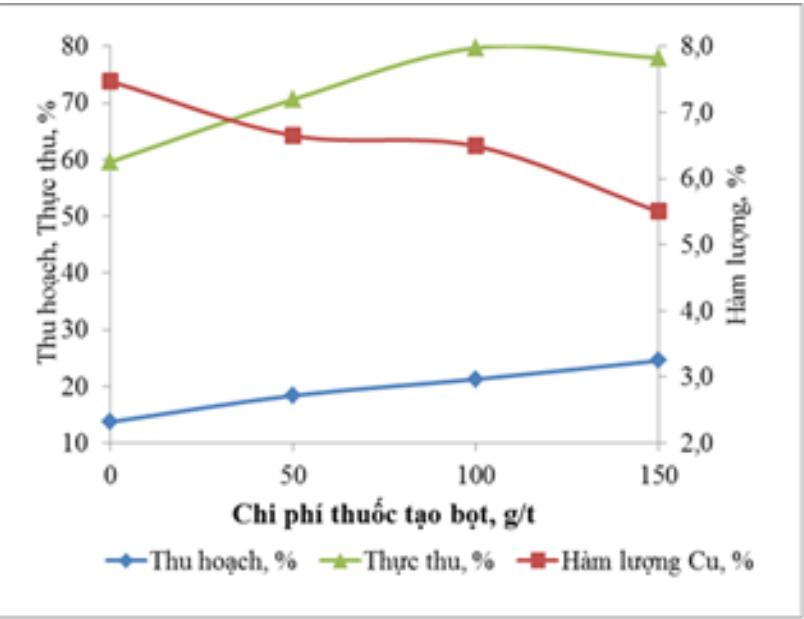

Hình 8. Đồ thị biểu diễn ảnh hưởng chi phí thuốc tạo bọt đến hiệu quả tuyển.

Sơ đồ tuyển vòng kín 2 (Hình 10) ưu tiên thực thu quặng tinh đồng, sử dụng phương pháp tuyển nổi kết hợp tuyển từ để thu được sản phẩm quặng tinh đồng có mức thu hoạch $6,40 \%$, hàm lượng đồng là $20,38 \% \mathrm{Cu}$, thực thu đạt 75,35\% Cu, kết quả tuyển như Bảng 4.

Bảng 4. Kết quả thí nghiệm sơ đồ vòng kín 2.

\begin{tabular}{|c|l|c|c|c|}
\hline TT & Tên sản phẩm & $\begin{array}{c}\text { Thu } \\
\text { hoạch, } \%\end{array}$ & $\begin{array}{c}\text { Hàm lượng } \\
\mathrm{Cu}, \%\end{array}$ & $\begin{array}{c}\text { Thực thu } \\
\mathrm{Cu}, \%\end{array}$ \\
\hline 1 & Quăhn tinh đồng & 6,40 & 20,38 & 75,35 \\
\hline 2 & Thải & 93,60 & 0,46 & 24,65 \\
\hline \multicolumn{2}{|c|}{ Quặng cấp } & 100,00 & 1,73 & 100,00 \\
\hline
\end{tabular}

Sơ đồ thí nghiệm tuyển vòng kín 2 (Hình 10) được đề xuất để tính toán, lắp đặt và chạy thí nghiệm mẫu lớn trên dây chuyền bán công nghiệp. 


\subsection{Kết quả thí nghiệm tuyển trên dây chuyền quy mô bán công nghiệp}

Nhóm nghiên cứu đã tiến hành tính toán, lắp đặt, chạy thử và hiệu chỉnh không tải, có tải trên dây chuyền tuyển quy mô pilot năng suất 120 $\mathrm{kg} / \mathrm{h}$. Sau khi dây chuyền chạy ổn định, tiến hành lấy mẫu đánh giá các chỉ tiêu công nghệ tuyển. Kết quả thí nghiệm tuyển trên dây chuyền quy mô pilot được trình bày tại Bảng 5 . Sản phẩm quặng tinh đồng có mức thu hoạch 6,28\%, hàm lượng đồng đạt 20,23\% Cu, thực thu đồng trong sản phẩm quặng tinh là 72,55\%. Quặng thải có hàm lượng đồng là $0,51 \%$.

Bảng 5. Kết quả thí nghiệm trên dây chuyền bán công nghiệp.

\begin{tabular}{|c|l|c|c|c|}
\hline TT & Tên sản phẩm & $\begin{array}{c}\text { Thu } \\
\text { hoạch, } \%\end{array}$ & $\begin{array}{c}\text { Hàm lượng } \\
\mathrm{Cu}, \%\end{array}$ & $\begin{array}{c}\text { Thực thu } \\
\mathrm{Cu}, \%\end{array}$ \\
\hline 1 & Quặng tinh đồng & 6,28 & 20,23 & 72,55 \\
\hline 2 & Thải & 93,72 & 0,51 & 27,45 \\
\hline \multicolumn{2}{|c|}{ Quặng cấp } & 100,00 & 1,75 & 100,00 \\
\hline
\end{tabular}

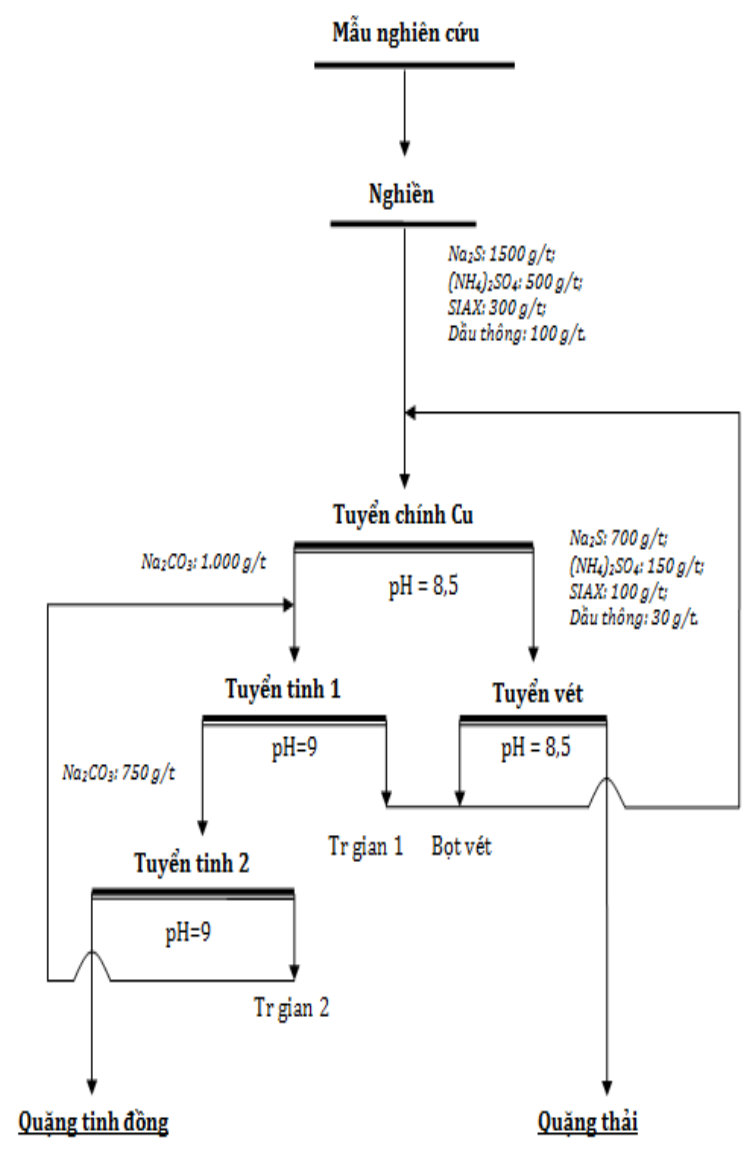

Hình 9. Sơ đồ thí nghiệm tuyển nổi vòng kín 1.

\section{Kết luận}

Quá trình nghiên cứu phát triển và hoàn thiện công nghệ tuyển quặng đồng oxit Sơn La của công ty Cổ phần Khoáng sản Tây Bắc đã đạt những kết quả nổi bật như sau:

+) Đã xác định thành phần vật chất mẫu quặng đồng oxit Sơn La, từ đó định hướng công nghệ tuyển.

+) Kết quả nghiên cứu phát triển và hoàn thiện công nghệ quy mô phòng thí nghiệm đã xác lập các chế độ công nghệ tuyển tối ưu như sau:

* Chế độ khâu tuyển nổi:

Tuyển chính:

- Độ mịn nghiền: 90\% cấp - 0,074mm;

- Nồng độ pha rắn: $R=25 \%$; Môi trường tuyển $\mathrm{pH}=8,5$;

- Chi phí thuốc sunfua hóa $\mathrm{Na}_{2} \mathrm{~S}: 1500 \mathrm{~g} / \mathrm{t}$;

$\left(\mathrm{NH}_{4}\right)_{2} \mathrm{SO}_{4}: 500 \mathrm{~g} / \mathrm{t}$;

- Chi phí thuốc tập hợp SIAX: 300 g/t;

- Chi phí thuốc tạo bọt dầu thông: $100 \mathrm{~g} / \mathrm{t}$.

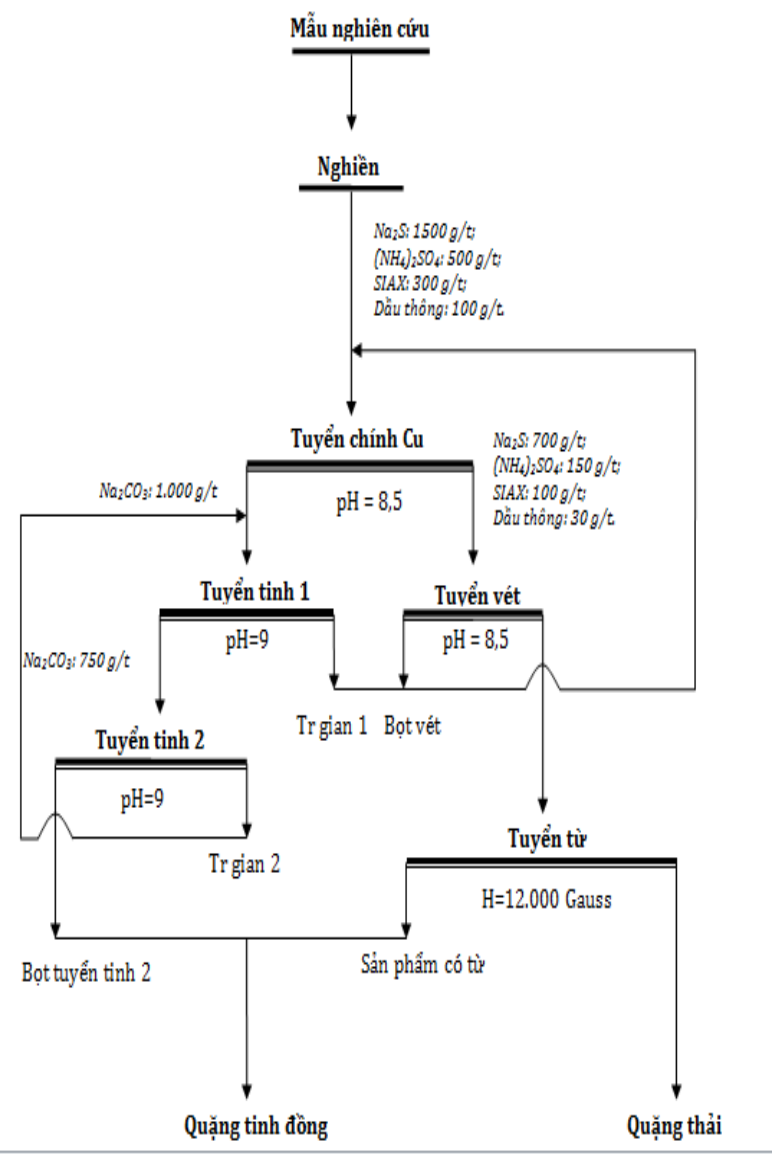

Hình 10. Sơ đồ thí nghiệm tuyển nổi vòng kín 2. 
Tuyển vét:

- Chi phí thuốc sunfua hóa $\mathrm{Na}_{2} \mathrm{~S}: 700 \mathrm{~g} / \mathrm{t}$; $\left(\mathrm{NH}_{4}\right)_{2} \mathrm{SO}_{4}: 150 \mathrm{~g} / \mathrm{t}$;

- Chi phí thuốc tập hợp SIAX: 100 g/t;

- Chi phí thuốc tạo bọt dầu thông: $30 \mathrm{~g} / \mathrm{t}$. $\mathrm{pH}=9$.

Tuyển tinh 1: Chi phí $\mathrm{Na}_{2} \mathrm{CO}_{3}: 1.000 \mathrm{~g} / \mathrm{t}$;

Tuyển tinh 2: Chi phí $\mathrm{Na}_{2} \mathrm{CO}_{3}: 750 \mathrm{~g} / \mathrm{t} ; \mathrm{pH}=9$.

* Chế độ khâu tuyển tù̀ thu hồi đồng tù̀ ngăn máy tuyển nổi:

- Nồng độ cấp liệu $R / L=15 \%$

- Cường độ từ trường $H=12.000$ Gauss.

+) ở quy mô phòng thí nghiệm đã xây dựng được sơ đồ công nghệ tuyển hợp lý đối với mẫu quặng đồng oxit Sơn La. Kết quả thu được từ sơ đồ là sản phẩm quặng tinh đồng có hàm lượng đạt 20,38\% Cu, thực thu đồng tương ứng đạt 75,35\%. Quặng thải có hàm lượng là $0,46 \% \mathrm{Cu}$.

+) Đã tính toán, lắp đặt và chạy không tải, có tải trên dây chuyền thí nghiệm quy mô pilot với năng suất $120 \mathrm{~kg} / \mathrm{h}$ thu được sản phẩm quặng tinh đồng có mức thu hoạch 6,28\%, hàm lượng đồng đạt 20,23\% Cu, thực thu đồng trong sản phẩm quặng tinh là 72,55\%, quặng thải có hàm lượng đồng là $0,51 \%$.

\section{Đóng góp của các tác giả}

Tác giả Trần Thị Hiến hình thành ý tưởng, triển khai các nội dung và hoàn thiện bản thảo cuối của bài báo; tác giả Phạm Đức Phong cùng triển khai các nội dung và đọc bản thảo bài báo.

\section{Tài liệu tham khảo}

Hợp đồng số 26/KHVL ngày 02/03/2020 thực hiện Dự án SXTN nhánh KHCN giữa Viện Khoa học Vật liệu và Viện Khoa học và Công nghệ Mỏ - Luyện kim.

Nguyễn Bơi, (1998). Tuyển nổi. Nhà xuất bản Giao thông Vận tải.

QĐ 910 QĐ - TTg ngày 25/07/2018 Phê duyệt Quy hoạch thăm dò, khai thác, chế biến và sử dụng quặng vàng, đồng, niken, molipden đến năm 2025, có xét đến năm 2035.

Trần Thị Hiến, (2012). Nghiên cứu tính tuyển mẫu quặng đồng khu Làng Phát - Yên Bái. Viện Khoa học và Công nghệ Mỏ - Luyện kim, Hà Nội.

Xiong, K., Wen, S., Zheng, G., \& Bai, S. (2012). Flotation Research on Cuprite - type Oxide Copper in Xinjiang. Advanced Materials Research, 987 - 992.

Ziyadanoğulları, R., \& Aydın, F. (2005). A New Application for Flotation of Oxidized Copper Ore. Journal of Minerals \& Materials Characterization \& Engineering, 67 - 73. 